\title{
Integrated operation of sewer system and WWTP by simulation-based control of the WWTP inflow
}

\author{
K. Seggelke*, K.-H. Rosenwinkel**, P. A. Vanrolleghem ${ }^{* * *}$ and P. Krebs ${ }^{\star * * *}$ \\ *Institute for Technical and Scientific Hydrology (itwh), Sudhausweg1, D-01099 Dresden, Germany \\ (E-mail: k.seggelke@itwh.de) \\ **Inst. for Water Quality \& Waste Management, Univ. of Hanover, 30167 Hannover, Germany \\ ***BIOMATH, Ghent University, Coupure links 653, B-9000 Gent, Belgium

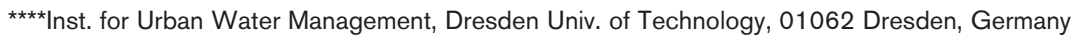

\begin{abstract}
In recent years numerical modelling became a standard procedure to optimise urban wastewater systems design and operation by integration. For dynamic control of the wastewater teatment plant (WWTP) inflow, a model-based predictive concept is introduced aiming at improving the receiving water quality. An on-line simulator running parallel to the real WWTP operation reflects the actual state of operation and provides this model information to a prognosis tool which determines the best option for the WWTP inflow. The investigations showed that it is possible to reduce the $\mathrm{NH}_{4}-\mathrm{N}$ peak concentrations in the receiving water by dynamic WWTP inflow control based on predictive scenario analysis.

Keywords Integrated modelling; model-based predictive control; off-line modelling; on-line modelling; WWTP-On-line-Simulation
\end{abstract}

\section{Introduction}

The integrated operation of the sewer network and the wastewater treatment plant (WWTP) is a requirement to reduce the total emission to the receiving water (i.e. Lijklema et al., 1993). It was the actual objective of various research projects to systematically investigate approaches to optimise the integrated system (Risholt et al., 2002; Rauch et al., 2002; Erbe et al., 2002; Meirlaen et al., 2002; Schütze et al., 2003).

The findings introduced in the following are the results of a research project in which the potential of on-line application of integrated modelling is examined (Seggelke, 2002; Seggelke and Rosenwinkel, 2002). In contrast to a strict and rigid limitation of the WWTP inflow, which e.g. in Germany commonly amounts to $2 Q_{s}+Q_{e}$ (twice the $85 \%$ ile of dry-weather hourly peak flow $Q_{s}$ plus the extraneous water flow $Q_{e}$ ), the varying treatment capacity should be identified on-line or even better through on-line or predictive simulations. These simulations should be coupled to the processes and made use of by adjusting the WWTP inflow such that combined sewer overflow (CSO) discharges and impacts to the receiving water are reduced. Prior to the development of this dynamic online system, we performed off-line simulations to identify the best maximum WWTP inflow rate with regard to receiving water quality.

Aside from the simulations, the investigation methods included experiments with a pilot-scale WWTP, measurement campaigns in the sewer system and the WWTP of the city of Hildesheim and in the receiving water.

The measurements showed that even with a high specific combined water storage volume in the sewer system, critical receiving water impacts may occur. At CSO events of low intensity the concentration in the CSO is higher than that in the WWTP effluent, while it is the other way round at high intensity events. The investigations on the effects of increased inflow rates on the WWTP operation showed that under proper conditions the effluent standards can be fulfilled with WWTP inflows up to $4 Q_{s}+Q_{e}$. In order to 
make use of the available treatment capacities under all circumstances, an appropriate control tool is necessary, while the treatment capacities are optimised by specific control strategies.

In the paper, the model approaches, the calibration based on measurements and the developed control tool will be introduced and (off-line and on-line) simulation results will be discussed.

\section{Description of the system}

\section{Catchment area and measurement campaigns}

The catchment of the City of Hildesheim is characterised by the information given in Table 1.

The following variables were measured on-line over a period of up to 2 years: flow rate to the WWTP and into the receiving water from each CSO structure, turbidity, UVSAC (Spectral Absorption Coefficient) in the overflow of one CSO structure, flow rate and various compound concentrations in the influent and effluent of the WWTP and in the river Innerste (e.g. $\mathrm{NH}_{4}-\mathrm{N}, \mathrm{NO}_{3}-\mathrm{N}, \mathrm{O}_{2}$ ). These measurements were used for model calibration and validation.

\section{Models}

Figure 1 describes the applied models and their coupling to simulate the Hildesheim-System.

\section{Verification of the calibrated model}

After thorough calibration (see Seggelke, 2002) the validation according to the data of more than a half year's period turned out very satisfactorily. Figures $2-5$ show the comparison of the model results and the measurements at the WWTP-Inflow, the WWTPEffluent and the receiving water. The high quality of the models allows their use for offline and on-line simulation.

\section{System of the On-line-Simulation with prediction}

Figure 6 shows the set-up of the adaptive predictive approach as it was implemented for some months at the Hildesheim WWTP. On the one hand the observer model and the predictive model for on-line control were linked to the treatment process and data flow, but on the other hand the real WWTP inflow could not be influenced by the model. The WWTP prognosis model is fed with results from KOSIM simulations, i.e. loads in the inflow, and from the on-line observer model (Obenaus et al., 1999) in SIMBA-Process (ifak, Magdeburg), which delivers the actual state of the biological process. Based on these inputs, the WWTP effluent quality can be predicted for various loading scenarios and allows us to estimate the maximum possible inflow and to choose the best control strategy for the WWTP operation in case of combined water inflow. Details on the

Table 1 Information about the catchment "City of Hildesheim"

\begin{tabular}{ll}
\hline Catchment area & 870 ha impervious \\
Inhabitants & $120,000 \mathrm{lnh}$, WWTP: 240,000 P.E. \\
Rainfall depth & $580 \mathrm{~mm} / \mathrm{a}$ \\
Sewer system (design: ATV A128) & Predominantly combined system; 11 CSOs with \\
& retention tanks \\
& Hydraulically separated sub-catchments, each \\
Connected to a CSO (Figure 1)
\end{tabular}




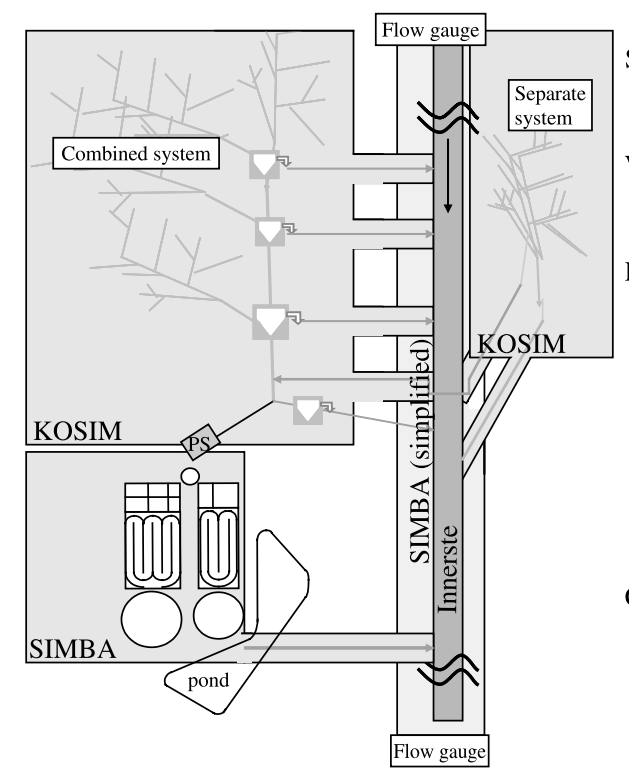

Sewer System: hydrological model KOSIM (itwh, Hanover)

WWTP: ASM2d, SIMBA (ifak, Magdeburg)

Receiving Water: SIMBA Hydraulics: simplified with translation approach and CSTR cascade, $\mathrm{NH}_{4}-\mathrm{N}$ : estimated by mixing approach, $\mathrm{O}_{2}$ : ASM2 with parameter identification similar to RWQM1, 20 CSTR reactors

Coupling of the models: sequential with automated data-transfer

Figure 1 Overview of the models used

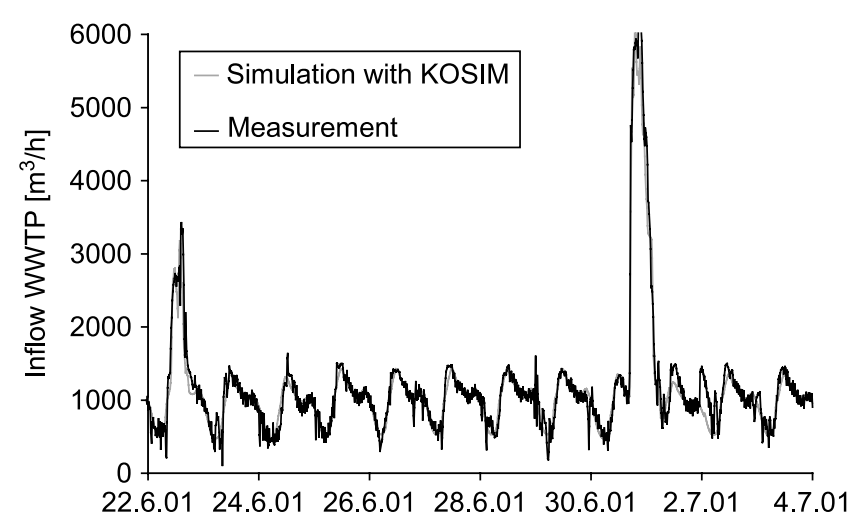

Figure 2 Inflow to the WWTP

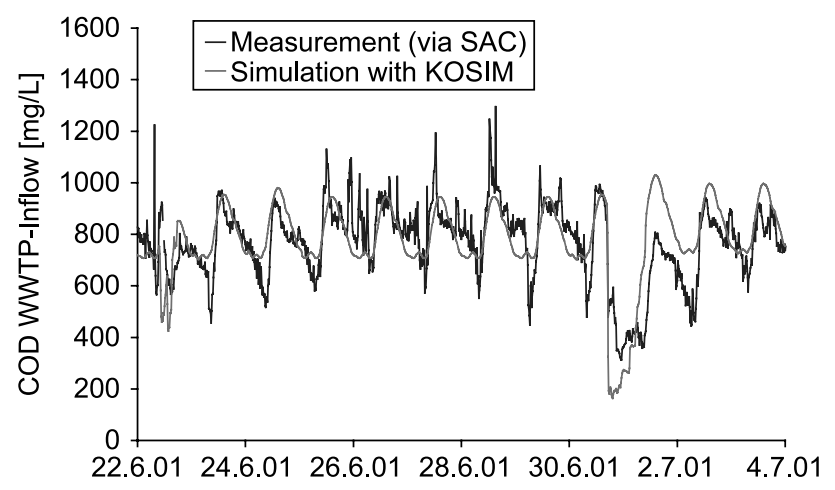

Figure 3 Comparison: COD conc. at WWTP inflow 


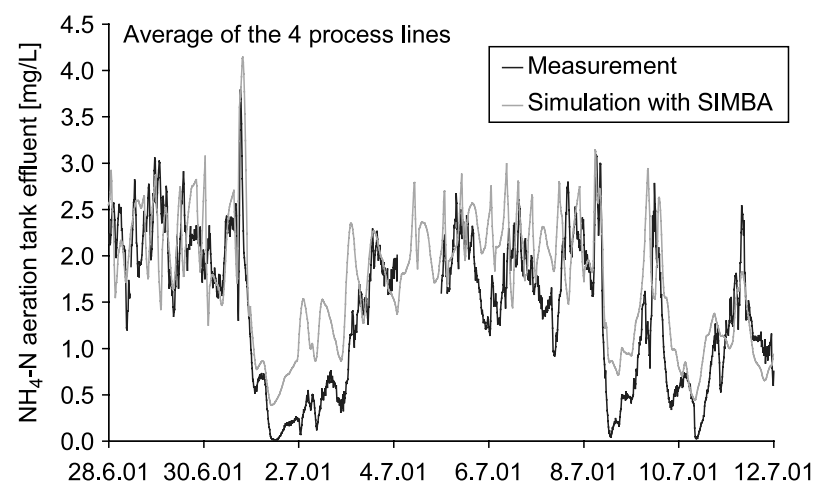

Figure $4 \mathrm{NH}_{4}-\mathrm{N}$ conc. in WWTP-Effluent

model, the prerequisites for the on-line implementation (i.e. fractionation, influent generation) and the WWTP control strategies can be found in Seggelke (2002).

\section{Results of integrated simulations - off-line}

Figure 7 shows the simulation results for four different operating scenarios for an intense (left, $23.3 \mathrm{~mm}$, and a weak (right, $11.1 \mathrm{~mm}$ ) rain event. The results combine the $\mathrm{NH}_{4}-\mathrm{N}$

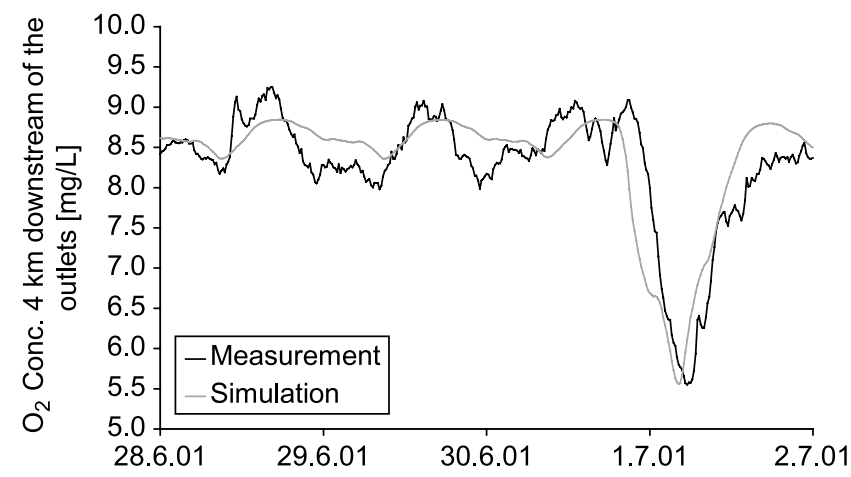

Figure $5 \mathrm{O}_{2}$ conc. in the receiving water $4 \mathrm{~km}$ downstream of the outlets of the WWTP

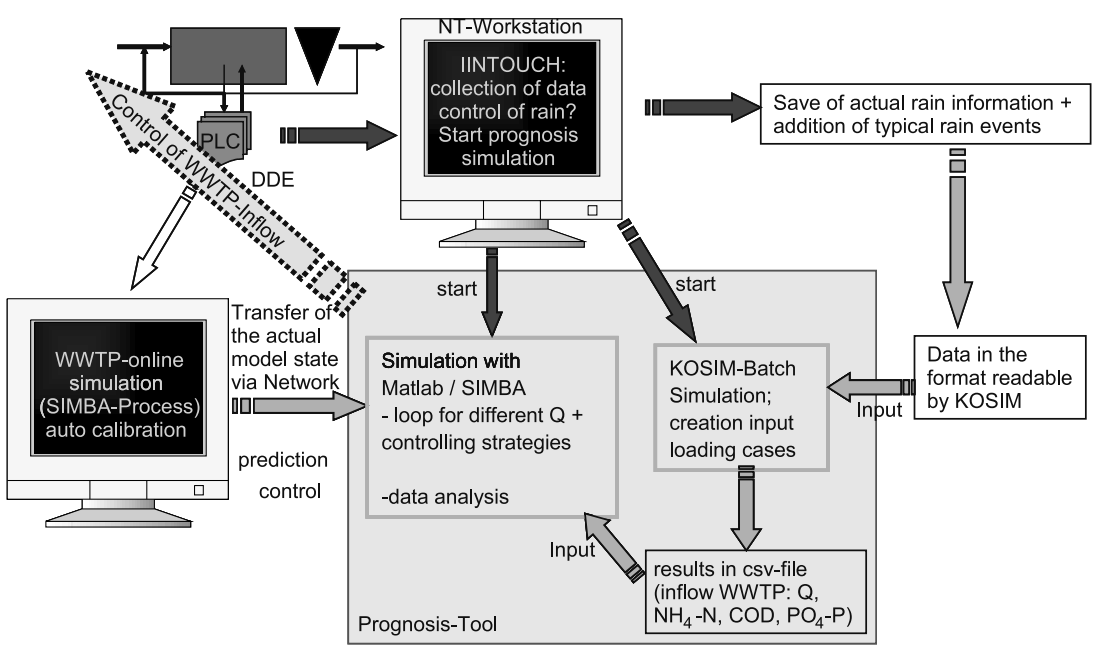



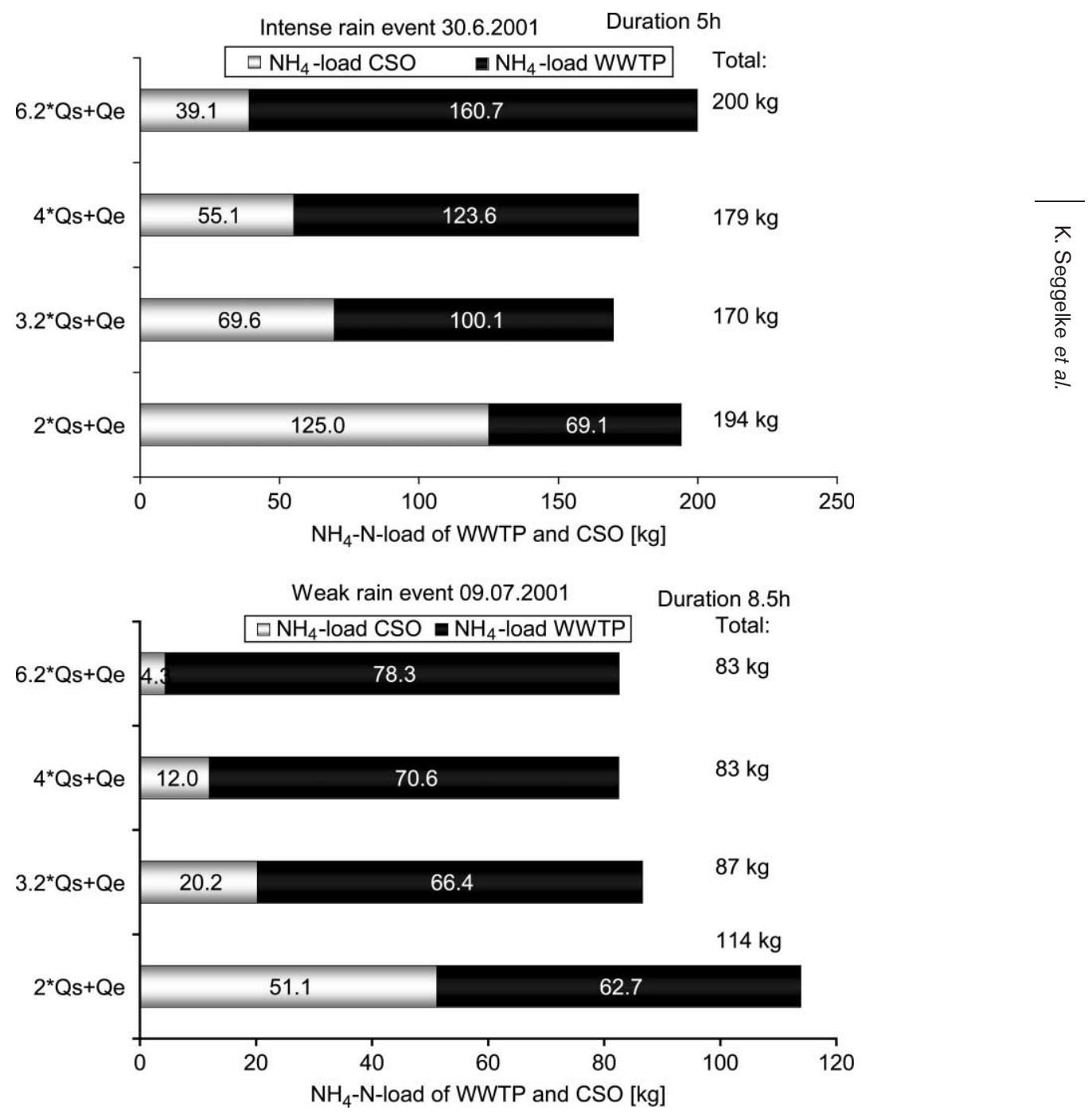

Figure 7 Results of the integrated off-line simulation: $\mathrm{NH}_{4}-\mathrm{N}$-loads of WWTP and CSO over event duration

loads of CSO structures and WWTP effluent. While for the intense event a minimum total emission was found for a maximum WWTP inflow of around $3.2 * Q_{s}+Q_{e}$, the optimum was found around $4 * Q_{s}+Q_{e}$ for the weak event.

In Figure 8 the water-quality oriented evaluation of the loading cases is shown. As an example, the $\mathrm{NH}_{4}-\mathrm{N}$ concentration in the receiving water Innerste $0.3 \mathrm{~km}$ downstream of the WWTP effluent is shown for the same events as discussed in Figure 7.

In the simulated rain events, the dilution by the flow of the Innerste is distinct enough and temperature and $\mathrm{pH}$-value are low enough to avoid critical $\mathrm{NH}_{3}-\mathrm{N}$ concentrations. The $\mathrm{NH}_{4}-\mathrm{N}$ concentration-peak exhibits values between 1.1 and $1.4 \mathrm{mg} / \mathrm{L}$, depending on the maximum accepted WWTP inflow (Figure 8). The simulation results show that for the intense rain event (Figure 8, left), the WWTP-Inflow 6.2 $Q_{s}+Q_{e}$ induces the highest, and $3.2 Q_{s}+Q_{e}$ the lowest $\mathrm{NH}_{4}-\mathrm{N}$ concentration. For the weak rain event (Figure 8, right) the inflow $2 Q_{s}+Q_{e}$ is obviously the worst case.

The simulation study with the objective to optimise the constant maximum WWTP inflow elucidates that on the one hand a beneficial range of maximum combined water 


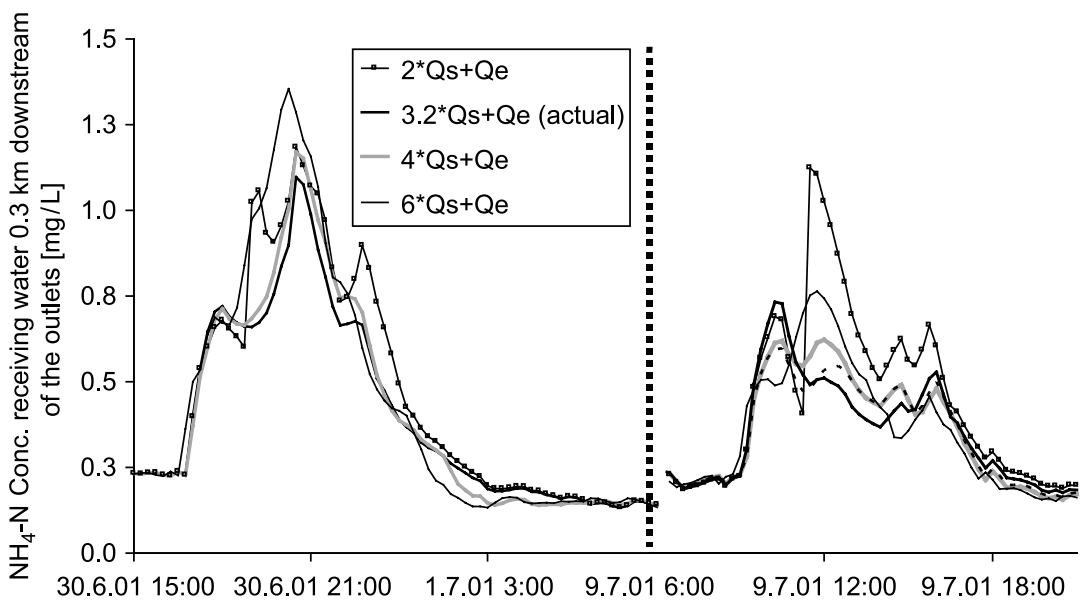

Figure 8 Result of the integrated simulation: $\mathrm{NH}_{4}-\mathrm{N}$ concentration in the receiving water $0.3 \mathrm{~km}$ downstream of the WWTP effluent; intense event (left), weak event (right)

treatment of the WWTP can be identified. However, on the other hand, there is no such thing as a fixed design case which is optimal for all conditions and events. For catchments with relatively small specific sewer storage volumes and free WWTP capacities, an increase of the WWTP inflow is beneficial and can reduce acute receiving water pollution.

Overall, this part of the study showed that the optimum WWTP inflow is case-dependent and should be included as a control parameter in the RTC concept of the sewer system in order to optimise the integrated operation with regard to concentrations in the river.

\section{Results of integrated simulations - on-line and predictive}

An important aspect of the entire tool is the prediction of the WWTP-Inflow. As described above, a hydrological model (KOSIM) predicts the future inflow to the WWTP and its composition on the basis of the actual rain information.

The results of the KOSIM-simulation are shown in Figure 9. The graphs result from the following simulations that were performed at different initial times: at time $t=0$

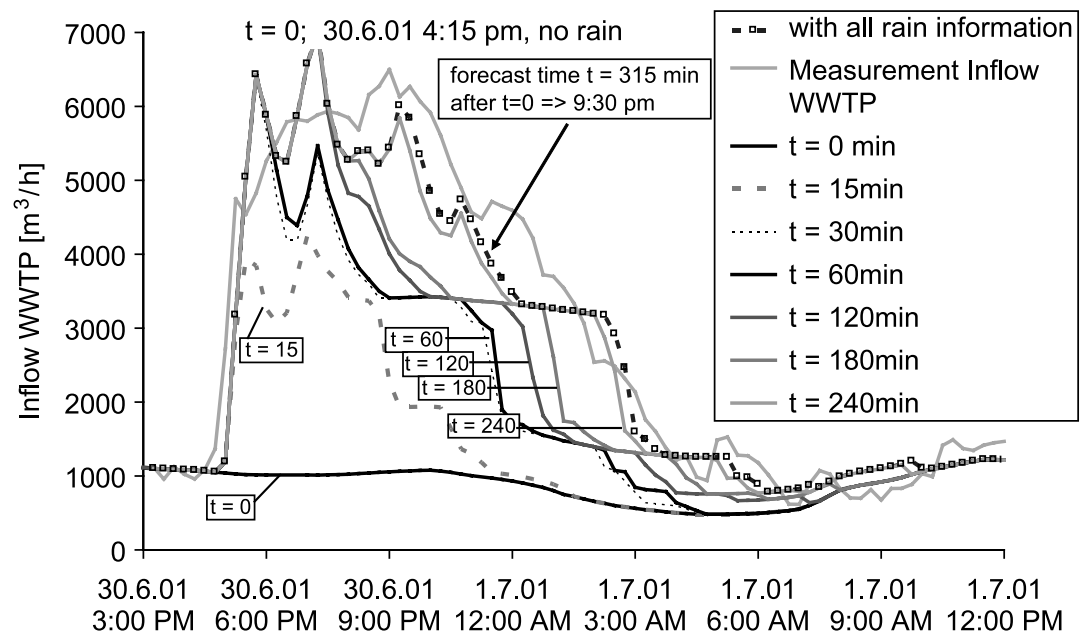


(last time step before the rain event starts), at $t=15 \mathrm{~min}$ (with first rain information), $t=$ 30 min (simulation of the WWTP-inflow for the next 48 hours based on 30 minutes' rain information), and so on. The comparison with the measured inflow shows that the resulting prognosis-quality may vary significantly between neighbouring time steps (e.g. predictions at $t=15 \mathrm{~min}$ and at $t=30 \mathrm{~min}$ ) while after a certain initial phase the prognosis becomes quite reasonable for approximately the coming $45 \mathrm{~min}$. For instance, at $t=30 \mathrm{~min}$ the flow increase is predicted quite well and between $t=30 \mathrm{~min}$ and at $t=60 \mathrm{~min}$ the predicted hydrograph does not change much.

In the next step, the simulation of the WWTP processes was started using the predicted WWTP-Inflow. The evaluation of the simulations and the comparison with the measured effluent values exhibit a satisfactory prediction, again for a time horizon of approximately 45 minutes.

Figure 10 shows the comparison of the constant settings and the suggestion of the prognosis simulation-tool. The prognosis simulation system was selecting the WWTP inflow for the next time step (of 15 minutes) out of the range between 2 and $4 Q_{s}+Q_{e}$ in steps of $0.2 Q_{s}+Q_{e}$. The following decision criteria were applied for the decision at every calculation time step:

1. WWTP-effluent values smaller than the threshold values and WWTP-process stable?

2. Calculation of the $\mathrm{NH}_{4}-\mathrm{N}$ concentration in the receiving water for each inflow load case

Concentration $\mathrm{NH}_{4}-\mathrm{N}_{\text {receiving water }}=\frac{\text { load }_{\text {effl WWTP }}+\text { load }_{\text {CSO }}+\text { load }_{\text {receiving water, } \text {, upstream outlet }}}{Q_{\text {effl } W W T P}+Q_{C S O}+Q_{\text {receiving water, upstream outlet }}}$

3. Comparison whether the concentration is lower or higher than that caused by the scenarios of the other WWTP inflow rates.

The suggestion of the prognosis model for the rain event shown in Figure 9 was achieved by consecutively increasing the WWTP inflow from $2.2 Q_{s}+Q_{e}$ in the initial $30 \mathrm{~min}$ after the rain started, over $3.0 Q_{s}+Q_{e}$ in the second phase ( $30 \mathrm{~min}$ to $90 \mathrm{~min}$ ), up to 3.2 $Q_{s}+Q_{e}$ in the remaining period.

Compared with the $\mathrm{NH}_{4}-\mathrm{N}$ concentrations in the Innerste resulting from the simulations with the constant settings of the WWTP-Inflow, the scenario on the basis of the

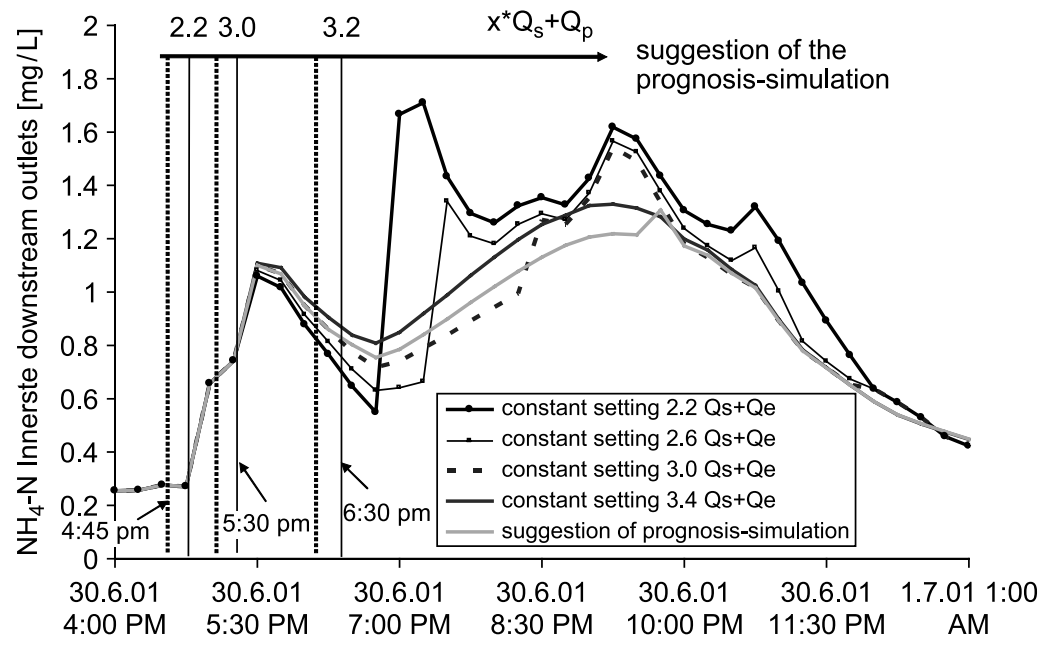

Figure 10 Prognosis-simulation results: $\mathrm{NH}_{4}-\mathrm{N}$ Concentrations in the receiving water 
event-dependent prognosis simulation achieved overall the best result, i.e. the lowest $\mathrm{NH}_{4}-\mathrm{N}$ concentrations in the receiving water.

The experiences with the observer model implemented in Hildesheim were diverse. On the one hand, the system was operated in a stable manner while on the other hand there were many problems with the on-line measurements. Moreover, systematic errors were observed, in spite of the installed inflow generator programme which is screening the measurement values automatically for correctness and, if necessary, generates surrogate values. It turned out to be very difficult to automatically detect slow drift type measurement errors. The consequence of incorrect inflow values is an incorrect actual model state of the WWTP Observer model and a bad prediction of the effluent, leading to a wrong selection of the maximum allowed inflow.

\section{Conclusions}

The paper gave an overview of an approach in which a simulation-based control of the WWTP inflow is used. The goal is to improve the overall performance of the sewer system and WWTP in the case of rain by applying integrated operation. This may become necessary for cases of sensitive receiving waters where high loads are discharged from the urban drainage and wastewater treatment system and critical concentrations of e.g. $\mathrm{NH}_{3}$ and $\mathrm{O}_{2}$ deteriorate the conditions in the aquatic system.

The simulation-based control approach includes the following elements (Seggelke, 2002):

- Calibrated models of sewer system, WWTP and receiving water (simplifications are possible)

- Inflow prognosis model, based on the calibrated model of the sewer system

- Observer model of the WWTP processes, based on the calibrated model of the WWTP, supported by on-line measurements of important parameters, with automated influent generation and model adaptation (Obenaus et al., 1999)

- Connection to the process logic control (PLC) of the WWTP

- Control strategies to find the best scenario

The investigation with the test system "city of Hildesheim" indicates the possible reduction of the overall impacts to the receiving water by means of WWTP inflow control. Critical concentrations can be avoided by improved integrated operation of the sewer system and the WWTP. Prerequisites for a promising system are the labour- and cost-intensive installations, measurement equipment, the model set-up and calibration as well as to overcome problems with incorrect or unstable measurements since those are important for a correct WWTP simulation of both the observer and the prognosis model. It is important to check such a system at regular intervals.

Further investigations should aim at identifying potential simplifications of the modelbased predictive system, gaining efficiency without losing reliability.

\section{Acknowledgement}

The research introduced in this paper was carried out at University of Hanover, Germany, and financed by the German Ministry for Education and Research (BMBF). The authors thank the employees of the WWTP Hildesheim for their friendly assistance.

\section{References}

Erbe, V., Frehmann, T., Geiger, W.F., Krebs, P., Londong, J., Rosenwinkel, K.-H. and Seggelke, K. (2002). Integrated Modelling as an analysing and optimisation tool for urban watershed management. Water 
Lijklema, L., Tyson, J.M. and Le Souef, A. (1993). Interactions between sewers, treatment plants and receiving waters in urban areas: a summary of the Interurba. 92 workshop conclusions. Water Science and Technology, 27(12), 1-29.

Meirlaen, J., Van Assel, J. and Vanrolleghem, P.A. (2002). Real time control of the integrated urban wastewater system using simultaneously simulating surrogate models. Water Science and Technology, 45(3), 109-116.

Obenaus, F., Rosenwinkel, K.-H., Alex, J., Tschepetzki, R. and Jumar, U. (1999). Components of a modelbased operation system for wastewater treatment plants. Water Science and Technology, 39(4), 103-111.

Rauch, W., Bertrand-Krajewski, J.-L., Krebs, P., Mark, O., Schilling, W., Schütze, M. and Vanrolleghem, P. (2002). Mathematical modelling of integrated urban drainage systems. Water, Science and Technology, 45(3), 81-94

Risholt, L.P., Schilling, W., Erbe, V. and Alex, J. (2002). Pollution based real time control of wastewater systems. Water Science and Technology, 45(3), 219-228.

Schütze, M., Erbe, V., Frehmann, T. and Seggelke, K. (2003). Application of integrated Modelling in Germany. Tilburg, 23-25 April 2003, IMUG Integrated Modelling User Group.

Seggelke, K. (2002). Integrierte Bewirtschaftung von Kanalnetz und Kläranlage zur Reduzierung der Gewässerbelastung. PhD-Thesis, Publication series, No. 124, Veröffentlichungen des Instituts für Siedlungswasserwirtschaft und Abfalltechnik, University of Hanover, Germany.

Seggelke, K. and Rosenwinkel, K.-H. (2002). Online-simulation of the WWTP to minimise the total emission of WWTP and sewer system. Water Science and Technology, 45(3), 101-108. 